
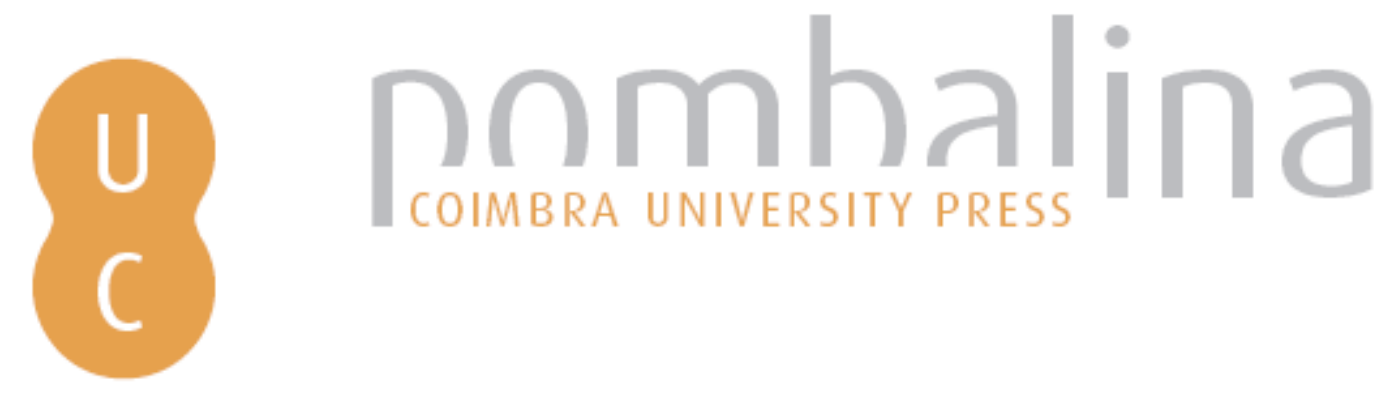

\title{
A presença dos gregos no pensamento hermenêutico de M. Baptista Pereira
}
Autor(es):
Silva, Maria Luísa Portocarrero Ferreira da

Publicado por: Imprensa da Universidade de Coimbra

URL

persistente:

URI:http://hdl.handle.net/10316.2/37049

DOI:

DOI:http://dx.doi.org/10.14195/978-989-26-1043-6_14

Accessed : $\quad$ 26-Apr-2023 11:18:37

A navegação consulta e descarregamento dos títulos inseridos nas Bibliotecas Digitais UC Digitalis, UC Pombalina e UC Impactum, pressupõem a aceitação plena e sem reservas dos Termos e Condições de Uso destas Bibliotecas Digitais, disponíveis em https://digitalis.uc.pt/pt-pt/termos.

Conforme exposto nos referidos Termos e Condições de Uso, o descarregamento de títulos de acesso restrito requer uma licença válida de autorização devendo o utilizador aceder ao(s) documento(s) a partir de um endereço de IP da instituição detentora da supramencionada licença.

Ao utilizador é apenas permitido o descarregamento para uso pessoal, pelo que o emprego do(s) título(s) descarregado(s) para outro fim, designadamente comercial, carece de autorização do respetivo autor ou editor da obra.

Na medida em que todas as obras da UC Digitalis se encontram protegidas pelo Código do Direito de Autor e Direitos Conexos e demais legislação aplicável, toda a cópia, parcial ou total, deste documento, nos casos em que é legalmente admitida, deverá conter ou fazer-se acompanhar por este aviso. 
politica no Brasil do sécu

Categorias aristotélicas por Silvestre Pinheiro Ferreira - Musas errantes: tesouros da Antiguidade Clássica no labirinto da Biblioteca Nacional Brasileira - Eudoro de Sousa e a Mitologia • Câmara Cascudo em defesa de Epicuro - Medéia carioca - Ecos de Platão em Vergílio Ferreira - Imaginário clássico na poesia de António Arnaut - Motivos clássicos na poesia novilatina em Portugal: Manuel da Costa - Uma Ifigénia portuguesa: "Noite escura" de João Canijo • Uma leitura de Mau Tempo no Canal de Vitorino Nemésio $\bullet A$ phýsis grega e o Brasil: as viagens de Von Martius $\bullet$ Fantasia para dois coronéis e uma piscina. Ecos clássicos num contexto do séc. XX

\section{A RECEPÇÃO DOS CLÁSSICOS EM PORTUGAL E NO BRASIL}

Maria de Fátima Silva Maria das Graças de Moraes Augusto COORDENAÇÃo 


\section{SÉRIE MITO E (RE)ESCRITA}

ISSN: $2182-8814$

\section{PERIODICIDADE: Anual}

Apresentação: Poetas, pintores, escultores, na Antiguidade, familiarizados com mitos antigos de deuses e de homens, que cristalizavam experiências, interrogaçóes, respostas quanto à existência do homem no tempo e no mundo, em mitos se inspiraram, em contínua criação-recriaçẩo, para neles verterem a sua própria experiência temporal, com todos os desassossegos e inquietaçóes, com todo o espanto, horror ou encantamento pela excecionalidade da ação humana, que rasga ou ilumina fronteiras de finitude. Esses percursos da criação merecem, hoje, a atenção e análise dos Estudos Literários e, como não podia deixar de ser, dos Estudos Clássicos, muito peculiarmente. Importa, pois, proceder à publicação sistemática de estudos deste cariz, que se destaquem pela qualidade científica e pela originalidade, sendo dedicados, sobretudo, a autores de língua portuguesa. Assim se dá corpo à linha editorial MITO E (RE)ESCRITA.

Este livro, realizado no âmbito do Convénio de Cooperação Académica entre o CECH - Centro de Estudos Clássicos e Humanísticos da UC - e o PRAGMA - Programa de Estudos de Filosofia Antiga da UFRJ -, reúne um conjunto de estudos sobre a recepçáo de temas e modelos greco-latinos na literatura e cultura de Portugal e Brasil.

A sua originalidade resulta da participação de diferentes culturas e das especialidades académicas diversas dos investigadores que nele participam, provenientes da Literatura, da Filosofia e da História Antiga. O lapso de tempo abrangido, que vai do séc. XVI ao XX, permite uma visáo de conjunto da evoluçáo operada no perfil cultural de ambos os países e na definição de um trajeto em boa parte comum. 


\title{
A presença dos gregos no pensamento bermenêutico de M. Baptista Pereira
}

(Greek presence in Miguel Baptista Pereira's philosophical thought)

\author{
Maria Luísa Portocarrero Ferreira da Silva \\ Universidade de Coimbra \\ (mlp600@gmail.com)
}


Página deixada propositadamente em branco 
Resumo - Este texto procura pensar a presença decisiva do pensamento filosófico grego na filosofia hermenêutica de M. Baptista Pereira, sabendo no entanto que a sua filosofia sofre uma influência decisiva da filosofia cristá.

Palavras-Chave - valorização do núcleo socrático da filosofia grega; crítica ao modelo metódico moderno do sentido do filosofar; interpretaçáo do diálogo Íon de Platão.

Abstract - This text tries to think the decisive presence of Greek philosophical thought in philosophical hermeneutics of M. Baptista Pereira, knowing however that their philosophy suffers a decisive influence of Christian philosophy.

KEYwORDs - Appreciation of the core of Socratic Greek philosophy; critique of modern methodical philosophizing; Plato's dialogue Ion interpretation.

I-

Foi M. Baptista Pereira, saudoso professor desta Universidade, quem introduziu a Hermenêutica Filosófica nos curricula do curso de Filosofia de Coimbra. Profundamente crítico do saber morto, repetitivo e doxográfico que se transmite, como um conteúdo acabado, sem qualquer questionamento vivo e assim abafa toda a possível novidade e originalidade em Filosofia, Baptista Pereira sempre perseguiu, nas suas aulas e reflexóes, a pergunta originária por detrás dos textos e juízos formulados. Neste sentido, fomentou o diálogo vivo com a tradição, diálogo que a Hermenêutica filosófica de H.-G. Gadamer procurava já ressuscitar, como o verdadeiro método da filosofia. O lugar em que surge e se torna problemática a questão do sentido da vida é para o filósofo de Coimbra o diálogo interior que se abre às grandes questōes que sempre motivaram o filosofar e que assim se deixa fecundar pelas respostas da tradição.

É, de facto, a partir do diálogo da consciência consigo mesma, de raiz grega, que se póe, para M. Baptista Pereira, a questáo filosófica do sentido. Podemos dizer que toda a sua filosofia perseguiu esta questão ${ }^{1}$, em diálogo com a história da filosofia, numa multiplicidade de escritos de que se prepara agora a edição das obras completas.

1 A questão do sentido último da vida parece-nos ser o problema filosófico central da sua obra referida à existência enquanto decurso que se estende do nascimento até à morte e ainda à problemática do significado da temporalidade. Podemos dizer que esta grande questão aparece ainda ligada à ideia de um significado para a vida e, depois, numa linha mais reflexiva, manifesta-se como capacidade de examinar e julgar criticamente a vida. 
Foi pois o acesso interrogativo ao sentido, mediado pela dialética pergunta-resposta e recebido da tradição platónico-agostiniana, que o Professor sempre quis realçar nos seus escritos. Daí a sua dedicação à Hermenêutica filosófica e a sua crítica do ideal moderno do método marcado pela suspeita contra todo o recebido. Ao século da Hermenêutica dedicou três artigos²; dedicou ainda um a "Platấo e a hermenêutica filosófica» ${ }^{3}$ e outro ao trágico, intitulado «Sobre o Trágico» ${ }^{4}$ Vamos hoje partir destes textos e ainda de um outro artigo "Originalidade e novidade em Filosofia" ${ }^{5}$, pois eles permitem-nos analisar esquematicamente os grandes eixos do seu filosofar. Digamos desde já que muito longe de querer limitar o problema do sentido a um subjetivismo cómodo e construtivista ou a uma filosofia mal definida, porque concebida a reboque da ciência, M. Baptista Pereira faz dela uma força envolvente que, apesar de pertencer sempre à intimidade de qualquer homem, o transcende sempre.

Duas experiências originais e irredutíveis, diz-nos, entreteceram, pelo cunho epocal que deixaram, "o torráo do pensamento filosófico europeu: a experiência grega da physis e a bíblica de tempo. Se do primeiro tipo de experiência herdamos, como traço dominante, o conceito de archê ou origem absoluta e princípio dinâmico de todas as coisas, o segundo transmitiu-nos, com particular incidência, a ideia de movimento e de advento de um sentido irreversível que desperta, de modos sempre diferentes, a surpresa e a esperança, a responsabilidade e a seriedade da nossa existência» ${ }^{6}$.

Interessado sobretudo na experiência bíblica de tempo e na sua riqueza para a meditação filosófica sobre o sentido ou não sentido do existir, é no entanto a densidade das interpretaçóes da origem que Baptista Pereira persegue em todo o seu filosofar, sempre construído em diálogo com grandes filósofos do Ocidente ou com problemas reais aparecidos ao longo da história. É aliás neste contexto, atualmente estranho, do poder ser tocado pela participação hermenêutica num pro-

\footnotetext{
2 Pereira 2000: 3-62; Pereira 2000: 189-259; Pereira 2001: 3-68.

3 Pereira 1995: 357-363.

4 Pereira 1991: 237-243.

5 Pereira 1997: 1-113.

6 Pereira 1997: 3.
} 
blema comum, a que o passado já respondeu (com as suas categorias), que podemos entender o impacto dos gregos, na filosofia de Miguel Baptista Pereira, nomeadamente, de Platão e Aristóteles. Retomando a pergunta de Kurt von Fritz, o professor questiona-se mesmo sobre "O que é que torna os Gregos antigos táo importantes para um autor apaixonadamente comprometido na procura de uma solução para problemas do nosso tempo aparentemente novos e únicos? ( ...). Embora os gregos se tenham debatido entre diferentes e até contraditórias respostas aos problemas suscitados pela razão nascente, jamais deixaram de se ouvir uns aos outros»?

Poder ouvir (ou ler) o outro, perceber que ele pode ter algo a dizer-nos, é para Baptista Pereira uma operação hermenêutica fundamental em que a oferta de sentido atinge o seu objetivo, pois o que é ouvido ou lido é apropriado num processo dinâmico de compreensão, em que o ouvinte ou leitor intervém com horizontes particulares vindos da sua perspetiva histórica. A cadeia formada pelo poeta, pelo intérprete, pelo ouvinte ou leitor representa a articulação do "ato hermenêutico integral" a que se chama hoje "círculo hermenêutico" e a que já o diálogo Íon de Platão chamava «doação divina partilhada por muitas vozes e interpretaçóes» ${ }^{8}$.

A filosofia parte sempre de pressupostos, de um efeito histórico das respostas do passado, que nos permitem retomar, a partir das nossas próprias questóes, a grande questáo que a todos une, logo ela tem na sua origem uma doação cujo correlato é o ouvir um excesso de sentido inesgotável, que é por sua vez a raiz das diferenças históricas que formam a tradição. A procura grega da origem é em Baptista Pereira mediada pelo novo, sendo pois o problema da temporalidade da origem e do fundamento o que o ocupa na tarefa que a si mesmo se impõe: pensar filosoficamente a história da filosofia, contra a tendência para confundir a obra filosófica «com uma banda registadora ou um trabalho de computador tecnicamente imperfeito"'. Distinguir claramente na história da filosofia a fonte documental da fonte origem, eis o seu grande escopo, no diálogo que vai estabelecendo com a tradição, ao longo de toda a sua obra.

\footnotetext{
7 Pereira 1988: 217.

8 Pereira 1995: 371.

9 Pereira 1997: 4-5.
} 
No contexto deste esforço, para contestar a redução da história da filosofia a pura doxografia, surge-lhe inevitavelmente a pergunta pelo essencial do pensamento grego. A dialética socrática da pergunta e da resposta, que define o lugar da finitude humana no universo do sentido, é então reabilitada como originária contra o modelo económico da racionalidade que o primado moderno do método vai instalar na ordem filosófica do sentido. A partir da Modernidade, com efeito, relembremos, a via da dúvida e todo o sistema de regras inerentes ao método passam a ritmar a vida humana e a dar-lhe sentido. É pois contra um modelo de compreensáo do mundo reduzido ao prisma do pensamento calculador que nada recebe e tudo produz, a partir de um grau zero, que Baptista Pereira se insurge. Este modelo, hoje dominante, pensa, esqueceu de tal modo a finitude e o enraizamento no mundo, promoveu a tal ponto a construção, a certeza e a produçáo que hoje já não sabemos nem receber nem perguntar.

É pois a aliança entre o subjectum, palavra que para os gregos referia apenas o fundamento ou a substância que está por baixo de tudo (hypokeímenon), e $o$ eu que o homem diz de si mesmo na Modernidade, que M.B. Pereira contesta radicalmente, na linha da hermenêutica filosófica de M. Heidegger e H-.G. Gadamer. A elevação moderna da razão humana a fundamento é, em sua opinião, absolutamente redutora do sentido originário e acaba por transformar o saber em puro ato de produzir ou fabricar, no contexto da consagração da razão subjetiva, senhora e legisladora da natureza ${ }^{10}$.

$\mathrm{Na}$ raiz desta nova conceção de saber, que dominou o Ocidente desde a nossa modernidade e transformou completamente o próprio projeto epistémico herdado dos gregos, Baptista Pereira deteta uma fuga. Isto é, uma verdadeira rejeição do estar no mundo, acompanhada por uma necessidade vital que passa a ter como agente transformador o nascimento do sujeito e a sua vontade de reconhecimento e confirmação de si como diferente. Esta forma de pensar, lembra-nos, não se assemelha em nada ao sentir-se em casa e ao participar de forma contemplativa, cívica e prática da cidade grega, horizonte que deu origem ao nascimento ético e político do filosofar. O espírito da Antiguidade greco-romana, diz-nos, julgaria como «supremo absurdo transformar o mundo sem primeiro se interrogar sobre o valor ético desta mudança» ${ }^{11}$.

\footnotetext{
10 Pereira 1997: 17.

11 Pereira 1988: 217.
} 
Ora, foi justamente isto o que a modernidade fez, distinguindo-se das outras épocas pelo esquecimento do outro, e pela atitude de desconfiança e suspeita face a todo o recebido. Assim o homem moderno revolucionou as condiçóes da compreensão, passando a entender apenas aquilo que era capaz de produzir por si próprio; promoveu o narcisismo, rejeitando todo o envolvimento com o mundo e, nomeadamente, toda a receção da tradição. Acabou por transformar-se com o decorrer dos tempos no homo faber e animal laborans dos dias de hoje que não sabe já pensar e esquece, de forma quase ingénua, que é pela palavra que ele pode realizar, com outros, o sentido num espaço público de aparição.

É esta profunda redução teórico-técnica do sentido do saber, que marcou todo o Ocidente a partir da modernidade, que Batista Pereira critica veementemente, situando-se assim na linha da análise hermenêutico-gadameriana do facto ciência e suas repercussóes políticas na evolução da Europa ${ }^{12}$. Com efeito, a nova mentalidade, que se iniciou na Filosofia a partir da modernidade, adota uma «visão intermitente do tempo" que parte do princípio de que o passado é algo ultrapassado, concluído e acabado, e esquece como ele age ainda nos projetos históricos do homem, afirmando-se na sua própria negação ${ }^{13}$. Para o nosso filósofo a tradição não pode reduzir-se a um somatório de proposiçôes veiculadas através do tempo, mas é, pelo contrário, entrega e libertação para o que nos é transmitido como realidade originária e a que temos que responder com a nossa diferença histórica ${ }^{14}$. Daí o valor de pensar com os gregos: é preciso retomar a ideia de filosofia, como amor à sabedoria, quando hoje podemos constatar que a aplicação dos conhecimentos científicos a áreas em que está em jogo a compreensão que o homem tem de si mesmo provoca conflitos, faz surgir perplexidades, e entrar em jogo fatores não científicos que defendem os seus direitos. Veja-se nomeadamente o surto das éticas aplicadas e da bioética no nosso mundo contemporâneo ou a própria discussão sobre a importância das humanidades em contextos científicos.

O que é que isto significa filosoficamente? Que a redução moderna da experiência às categorias prévias do sujeito e ainda às suas variantes gnosiológicas entretanto surgidas - a relação sujeito-objeto, a redução da verdade a simples adequaçáo, o esquecimento do fundamento e unidade do mundo,

\footnotetext{
12 Gadamer 1990: 87-105.

13 Pereira 1977: 8.

14 Pereira 1977: 9.
} 
a eliminação de toda a diferença ontológica e transcendência -, acaba por dar origem ao predomínio de uma razão unidimensional e económica que urge completar. Não podemos esquecer que esta racionalidade calculadora, apesar de já contestada pela Fenomenologia e pela Hermenêutica, ainda hoje nos governa. É neste sentido que Baptista Pereira a contesta, pensando como é preciso desconstruí-la, enquanto modelo único, isto é, fazer aparecer justamente o que ela tem abafado, a tradicional imagem de mundo veiculada pela literatura, pela narrativa histórica e pelo mito. É assim que o filósofo de Coimbra recorre por meio da hermenêutica, nomeadamente de Gadamer e Ricoeur, a dimensóes intemporais do horizonte de problematização filosófica que nos foi deixado pelos gregos.

O seu objetivo é uma reeducação do olhar filosófico em ordem a uma defesa do alargamento do sentido da experiência ${ }^{15}$ humana. Com efeito, em sua opinião, a suspeita ou fuga moderna do mundo, partem de uma experiência de penúria radical e transformam-se num perigoso cálculo empobrecedor, cujas consequências dáo origem ao niilismo e à crise económica dos dias de hoje. Caracterizam-se por dar à razáo humana o papel de um legislador que neste mundo apenas reconhece a sua própria virtuosidade, por outras palavras aquilo que sabe fazer. Assim se impôs no Ocidente o império do sujeito moderno, monológico, narcísico, que muito rapidamente passou da "utilizaçáo do mundo à fabricação do ser vivo", com todas as ameaças, promessas e perplexidades que esta possibilidade hoje encerra.

Ora, ao narcicismo moderno- causador de crise, porquanto no mundo o sujeito quer apenas confirmar os seus dotes, transformando-o num estaleiro onde confirma o seu próprio reconhecimento- Batista Pereira contrapóe, na linha da hermenêutica de Gadamer, o valor de uma receçáo da questáo originária que motivou a tradiçâao. Esta deve chegar-nos, em sua opiniâo, nomeadamente em momentos de crise, como horizonte de possibilidades a que devemos responder a partir da nossa diferença histórica, apropriandoa e modificando-a ${ }^{16}$. É assim que ganha relevo na sua filosofia a tarefa de recuperar os gregos, contra a ameaça da redução moderna e tecnológica dos possíveis da existência humana. É preciso nomeadamente recuperar, contra o modelo cartesiano, o conceito grego de método, como caminho e diálogo aberto à novidade do mundo.

Com efeito, o método moderno, ao sacrificar a novidade da experiência, estreitou o horizonte dos possíveis humanos, reduzindo-os ao âmbito

\footnotetext{
15 Pereira 1977: 10 sqq.

16 Pereira 1977: 9.
} 
do puramente empírico e palpável; marcou assim uma orientação exclusiva para o facto, para o positivo, o certo e seguro. E conseguiu-o à custa da fixação do sentido de uma experiência cuja repetição e verificabilidade estariam asseguradas ${ }^{17}$ apenas no laboratório.

Neste novo contexto, o que se considerou ser verdade só podia ser entendido contra a ordem temporal e quotidiana do estar no mundo. A razão moderna, técnica e económica, resultante da grande desconfiança face ao mundo- veja-se a dúvida metódica de Descartes - operou com efeito uma real transformação da nossa própria imagem de mundo. Simultaneamente, inventou um conceito de saber que na sua essência é entendido como saber para poder, prever e dominar, isto é, como um fazer e transformar. É este o modelo que Baptista Pereira rejeita, como originário, pois, nele perde-se o sentido e a densidade fundamental do receber, próprio de uma dimensão da razão humana ainda familiar aos gregos e que se encontra nomeadamente na experiência do exaiphnês da carta VII de Platáo, 341 c-d, e no Parménides, 156 c-e. Nos dois casos, fazer a experiência de algo significava ainda que algo nos sucede e atinge, derruba e sobretudo transforma, mudando perspetivas e formando interiormente.

É esta formaçáo interior do ser humano que começa a perder-se na Modernidade, perante o entusiasmo da transformação operatória do mundo que interessa ao pensamento filosófico de M. Baptista Pereira. Digamos pois que a ciência objetiva do mundo moderno parte de pressupostos quanto ao sentido da vida e do homem que Batista Pereira não partilha. Em vez de "entes", diz-nos o professor, «aparecem agora os "objetos" e o lugar do eidos (termo grego) clássico, de sentido predominantemente ontológico, é ocupado agora pela lei de constituição dos objetos no campo de representaçáo da consciência (...). Do real nada mais interessa para além de determinados aspetos, que, à maneira de casos individuais, caem sob o horizonte ou lei $a$ priori projetada pelo sujeito cognoscente» ${ }^{18}$. Nem o poético nem o literário, muito menos o trágico e seus mythoi são agora considerados como fonte de conhecimento ou formação. Com efeito, a formação que agora interessa é a metódica e calculadora, ou a positiva e operativa. Assim é abandonada a cultura da interioridade humana, tradicionalmente ligada à transmissão, à Ética em sentido socrático e aristotélico e em suma às humanidades.

\footnotetext{
17 Pereira 1977: 10.

18 Pereira 1977: 16-17.
} 
É claro que o espírito metódico da modernidade, pensa no entanto o filósofo de Coimbra, teve a sua importância no desenvolvimento do Ocidente e grandes vantagens: tecendo a sua complicada trama da planificaçáo, ele permitiu o progresso, o desenvolvimento, apurou extraordinariamente a ciência e esta trouxe ao mundo com a técnica, sua aliada, grande esperança e qualidade de vida. Mas ele deixou de lado como não significativas dimensôes autónomas da realidade, que fazem parte do horizonte de sentido do ser humano e que já os gregos detetavam como essenciais na sua relação vivida com o mundo.

Foram os gregos, diz-nos, citando Hegel, os primeiros a fazer do mundo a sua casa ${ }^{19}$. E sublinha: já Hegel situa o "gérmen da liberdade que pensa e a necessidade do nascimento da Filosofia entre os gregos, precisamente no torrấo da "Heimatlichkeit» existente no espírito do estarna-intimidade de si mesmo", representado objetivamente na existência física, civil, jurídica, moral e política, «neste caráter da historicidade bela, livre pela qual aquilo que eles (os Gregos) são, está também neles como Mnemosyne $»^{20}$.

Com esta valorização da familiaridade dos gregos com o ser, não reduzido ainda à natureza mecânica dos modernos, Baptista Pereira quer preparar para a Filosofia as condiçóes de um novo tempo pleno, começando por interrogar a essência da linguagem e, na esteira da sua filiaçáo bíblica, a natureza recetiva e auditiva da nossa relação primordial à linguagem. Desde Heraclito a Heidegger, lembra-nos, "perpassam através da densa cortina dos séculos testemunhos do primado do apelo, fundamento do falar e do responder humanos, convencendo-nos de que o núcleo mais íntimo do pensar é ouvir ${ }^{21}$.

Interpelação fundamental, espanto, diálogo da alma consigo mesma, eis os modos de pensar ainda não submetidos ao primado de uma relação meramente calculadora com o mundo pela qual se caracterizou o filosofar da modernidade. Neles se expressa uma mediação linguageira do sentido que a modernidade propositadamente descuidou, em prol do primado filosófico de uma outra linguagem: a matemática, rigorosa e artificial. Ora, é hoje

\footnotetext{
19 Pereira 1977: 27.

20 Hegel, G. W. F., Vorlesung uber die Geschichte der Philosophie, Ausg., Moldenhauer - Michel, K. M. (1971) I. Frankfurt, apud Pereira 1997: 27.

21 Pereira 1997: 60.
} 
na hermenêutica filosófica, corrente de pensamento que B. Pereira faz sua, que se reativa justamente uma certa tradição grega, reprimida, que acentua o primado da palavra "quando em vez do ponto de partida do "cogito", da consciência psíquica ou intencional e dos factos extra linguísticos, se apela para o mundo aberto pela linguagem natural, mundo da pré-reflexão e da pré-compreensão, o "mundo da vida", cuja densidade originária e nova muito nos dá que pensar»" ${ }^{22}$.

Como iremos ver, são justamente as raízes gregas desta Hermenêutica que o filósofo português quer reabilitar, nomeadamente, na sua reflexão sobre o diálogo Ion de Platão, feita no texto «Platão e a Hermenêutica Filosófica $»^{23}$.

III-

O sentido da vida é antes de mais uma capacidade vivida de sentir, de receber e gozar a vida e não uma pura construção. Os gregos já mostraram que tal capacidade se atesta através da linguagem ordinária, embora nesta não se esgote toda a experiência do sentido. Hoje a redescoberta hermenêutica desta linguagem dá-lhes razão e pode resumir-se deste modo: existe para nós uma verdade que nada tem de científico na aceção moderna deste termo, uma verdade que encontramos justamente por meio dos enredos que nos chegam, da narrativa histórica, do trágico e das histórias que contamos sobre nós. E nenhum discurso científico pode substituir-se a este tipo de encontro hermenêutico com uma ordenação do mundo e sua verdade. $\mathrm{Na}$ sua origem diz-nos Gadamer: «o problema hermenêutico da compreensão não é de modo algum um problema metódico. Não se interessa por um método de compreensão que permita submeter os textos ao conhecimento científico, tal como acontece a qualquer outro objeto da experiência. Nem sequer se ocupa basicamente em constituir um conhecimento seguro e de acordo com o ideal metódico da ciência. E, no entanto, trata-se nela de ciência e também de verdade. Quando se compreende a tradição, não só se compreendem textos, mas também se adquirem perspetivas e se conhecem

\footnotetext{
22 Pereira 1999: 323.

23 Pereira 1995: 357-363.
} 
verdades $\aleph^{24}$. Percebe-se, ao fim e ao cabo, aquilo de que se trata na experiência ética que nos envolve e ainda a própria expressividade do político.

Exposto ainda ao efeito dos mitos transmitidos pelos poetas e declamados pelos rapsodos, Platão traçou assim no diálogo Íon, lembra-nos Baptista Pereira, as bases de uma interpretação que apresenta em embriáo o primeiro esquema de uma Hermenêutica. Neste diálogo Baptista Pereira valoriza nomeadamente a metáfora da pedra magnética, usada por Sócrates, para explicar os elos da receção, da declamação e da interpretação poética. Esta metáfora mostra, de forma muito clara, que não é por meio de uma qualquer técnica que nasce o poema, a declamação e a interpretação. Mas sim mediante uma cadeia de pertença, de inspiração e de efeito histórico ${ }^{25}$ que se estabelece mediante a linguagem natural. «Sem inspiração, sem estar fora de si e para além da razão, o poeta não está em estado de criar poesia nem consultar oráculos». «Íon confessa que os seus olhos ficam rasos de lágrimas quando recita algum texto patético, os seus cabelos se erguem de medo e o coração começa a bater quando a cena declamada for aterrorizadora. Uma vez que o rapsodo desperta no público estes mesmos efeitos, o espetador é o último elo da cadeia magnética por onde passa a mensagem». E à pergunta insistente, sobre o campo de conhecimento que, fora da ciência e da técnica, distingue o rapsodo, Ion aponta a linguagem natural.

Em resumo, foi Platão que abriu o campo das múltiplas interpretaçóes dos poetas, protagonizado pelo talento dos rapsodos, ao mostrar através de Íon que existe uma verdade que resiste à abordagem científica e económica, verdade essa que começa na interpretação originária do poeta, continua na interpretação segunda do rapsodo e termina na apropriação de ouvinte ou leitor, que modifica ${ }^{26}$. Neste sentido diz-nos Baptista Pereira, "o vínculo de Platáo ao diálogo náo se deveria dissolver, pois ele jamais foi totalmente eleata, não defendeu uma ontologia de dois mundos e permaneceu " socrático", isto é um pensador consciente dos limites do saber humano vividos na sua profunda convicção religiosa, crítico da ambição do "saber técnico" dos seus adversários e defensor do diálogo como método da filosofia» ${ }^{27}$. Ser em diálogo significa «ser para além de si, pensar o outro e regressar a si como

\footnotetext{
24 Gadamer 1986: 1

25 Pereira 1995: 369.

26 Pereira 1995: 369 .

27 Pereira 1995: 371
} 
um outro ${ }^{28}$. Si mesmo como um outro, eis uma nova maneira de pensar a própria subjetividade a partir de uma noção de verdade que excede a verificabilidade e exatidão dos modernos.

É a substância socrática do pensamento de Platão e de todo o pensamento helénico que M. Baptista Pereira neste sentido valoriza e, tal como Gadamer, discute a leitura fisiológica, habitualmente feita, dos começos da Filosofia grega. «Não foi o tema da Natureza mas o dos múltiplos extravios do homem que se constitui objeto da Filosofia dos primeiros pensadores e não passa de ingenuidade hermenêutica interpretar o poema de Parménides em sentido ontológico $»^{29}$.

O que Baptista Pereira aprecia neste núcleo socrático da filosofia grega é a desilusão de Sócrates perante a Filosofia da natureza, tal como a verdadeira raiz da sua pergunta pelo bem e pelo sentido da praxis. Considera, no entanto, que a pergunta socrática pela virtude e pelo bem ficou submersa sob a construção aristotélica de um platonismo ontológico cindido em dois mundos e, por isso, considera com Gadamer que o verdadeiro sucessor do socratismo teria sido o Aristóteles da Ética ${ }^{30}$. «A procura do meio que anima toda a Ética e Política de Aristóteles é uma resposta da filosofia prática às ameaças da contradição trágica ${ }^{31}$, que acompanha o homem na sua compreensão do ser. Esta forma de meio-termo não anula o homem nem $\mathrm{o}$ mundo, preserva a identidade e as diferenças e constitui o sentido último da catarse trágica que transforma a Poética de Aristóteles num verdadeiro capítulo da Política ${ }^{32}$.

À presença de Aristóteles na formação da Fenomenologia hermenêutica contemporânea, nomeadamente, na de $\mathrm{M}$. Heidegger, dedicou ainda M.Baptista Pereira um outro texto ${ }^{33}$, extraordinariamente rico que analisaremos oportunamente.

\footnotetext{
28 Pereira 1995: 381

29 Pereira 1995: 380

30 Pereira 1995: 380-381.

31 Pereira 1988: 230.

32 Pereira 1988: 231.

33 Pereira 1995a: 481-510.
} 


\section{Bibliografia}

Gadamer, H. G. (1986), Gesammelte Werke, I. Hermeneutik I. Wahrheit und Methode. Grundzugeeiner philosophischen Hermeneutik. Tubingen: Mohr.

Gadamer, H. G. (1990), Das Erbe Europas. Frankfurt: Suhrkamp.

Pereira, M. B. (1977), "Introdução", in Peters, F. E. (ed.), Termos filosóficos gregos. Um léxico histórico. Lisboa: Fundação Calouste Gulbenkian: VI-XXV.

Pereira, M. B. (1988), "Modos de presença da filosofia antiga no pensamento contemporâneo", in As humanidades greco-latinas e a civilização do universal. Actas. Coimbra, Instituto de Estudos Clássicos: 209-310.

Pereira, M. B. (1991), "Sobre o trágico", in Medeia no Drama Antigo e Moderno. Actas. Coimbra, Centro de Estudos Clássicos e Humanísticos, Faculdade de Letras: 237-243.

Pereira, M. B. (1995), "Platão e a hermenêutica filosófica", Miscelânea em honra de Maria Helena Rocha Pereira, Humanitas 47: 357-383.

Pereira, M. B. (1995), “A presença de Aristóteles na génese de Ser e Tempo de M. Heidegger”, Biblos 71: 481-510.

Pereira, M. B. (1997), "Originalidade e novidade em Filosofia. A propósito da experiência e da história”. Homenagem a Victor Matos e Sá, Biblos 53: 1-113.

Pereira, M. B. (1999), "Experiência e sentido”, Miscelânea em honra de Sílvio Lima, Biblos 55: 289-401.

Pereira, M. B. (2000), “O século da hermenêutica filosófica: 1900-2000”, Revista Filosófica de Coimbra 17: 3-62.

Pereira, M. B. (2000), "O século da hermenêutica filosófica: 19000-2000", Revista Filosófica de Coimbra 18: 189-259.

Pereira, M. B. (2001), “O século da hermenêutica filosófica: 19000-2000”, Revista Filosófica de Coimbra 19: 3-68. 
Maria de Fátima Sousa e Silva é Professora Catedrática do Instituto de Estudos Clássicos da Universidade de Coimbra. Desenvolveu, como tese de doutoramento, um estudo sobre a Comédia Grega Antiga (Crítica do teatro na Comédia Grega Antiga), e, desde então, tem prosseguido com investigação nessa área. Publicou já traduções comentadas de nove comédias de Aristófanes, além de um volume com a tradução das peças e dos fragmentos mais significativos de Menandro.

Maria das Graças de Moraes Augusto é Professora Titular no Departamento de Filosofia do Instituto de Filosofia e de Ciências Sociais da Universidade Federal do Rio de Janeiro (UFRJ). A sua investigação sobre História da Filosofia Antiga abrange temas como Platão e a herança platónica, filosofia e conhecimento no pensamento antigo, filosofia e literatura na tradição antiga e recepção dos clássicos gregos no Brasil.

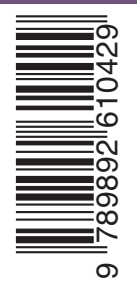


OBRA PUBLICADA

COM A COORDENAÇĀO

CIENTÍFICA
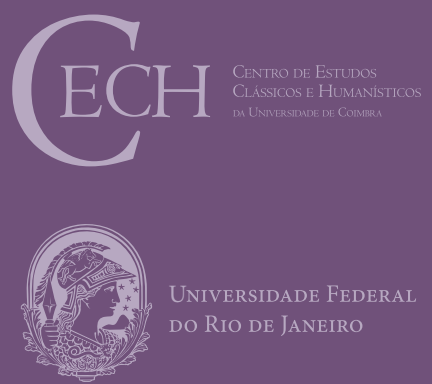

- U 